\title{
Retrospective Analysis of total COVID-19 Cases and Comparison of Case Fatality and Recovery Rates Among States of India After First and Second Phases of Lockdown
}

\author{
Narasimha Kumar G.V. ${ }^{1}$, Suneel Prajapati ${ }^{1}$, and Chitra ${ }^{2}$ \\ ${ }^{1}$ Affiliation not available \\ ${ }^{2}$ SRM College of Pharmacy
}

June 17, 2020

\begin{abstract}
Background \& Objectives: Testing rates, Case fatality rate (CFR), and Recovery rates (RR) are important parameters for assessing the measures taken in fighting during epidemics and pandemics. The present study was carried out to estimate average tests/day the, \% of confirmed cases and compare the CFR and RR during the pandemic of COVID-19 in the states of India after completion of the 1st\& 2nd phases of lockdown.Methods: The data were retrieved from accurate databases including the Ministry of Health and family welfare, Centre for Evidence-Based Medicine, COVID19 India, and the World Health Organization. States with total cases [?] 100 were included in the study and 1st phase of lockdown were commenced from 22nd March to 14th April 2020 \& 2nd phase of lockdown was from 15th April to 03rd May 2020Results: 32 states have reported COVID 19 as of 3rd May 2020. Average tests/day, RR have improved, and \% of confirmed cases, CFR have decreased among Indian states when compared after 1st\& 2nd phases of lockdown.Conclusion: Indian states have shown improvement with testing and mitigation measures to fight against COVID 19 as evidenced by a decrease in \% of confirmed cases, CFR, and improvement in RR. Apart from that, employing mass testing and epidemiological studies will expand the screening of asymptomatic cases. Also, case studies with a detailed medical history and scoring CFR alongside RR should be adopted in hospitals, which may be helpful in exactly pointing the hotspots of infection.
\end{abstract}

\section{Introduction}

Coronavirus disease 2019 (COVID-19) is the third coronavirus infection in the last two decades that was first arisen in the city of Wuhan, Hubei, province of China in December 2019. ${ }^{[1]}$ The unknown etiology of pneumonia later on confirmed as COVID-19 which is caused by Severe acute respiratory syndrome coronavirus 2 (SARS-CoV-2). It is a highly infectious viral disease and presented an unprecedented challenge before the world. COVID-19 has spread globally very rapidly since its first emergence in china, at present SARS-CoV-2, enclasps 215 countries world-wide and it's becoming the catastrophe of the century. A total of 32,72,202 confirmed cases and 230104 deaths were reported worldwide out of these 39,093 cases and 1306 deaths were accounted from India as of 3rd May 2020. ${ }^{[2]}$ However, the infection rate of COVID19 in India is reported to be 1.7 , significantly lower than in the worst affected countries ${ }^{[3,4]}$. At present, there is no specific vaccine available to prevent this viral disease and epidemiological, clinical shreds of evidence are suggesting several novel compounds, as well as medicines licensed for other conditions, that appear to have potential efficacy against COVID-19. ${ }^{[5]}$ Thus, in a way to combat the spread of this highly infectious disease, around one-third of the global population is now under lockdown to halt the spread of this highly contagious disease. ${ }^{[6]}$ India's first COVID-19 confirmed case was diagnosed in Kerala, in a student who has returned from Wuhan, China on January 30, 2020. Since the outbreak emerged in India, the number of cases has undergone a steady rise, 
and currently, several active cases were reported in different parts of India. While the number of cases has swelled in the last one month and cases have already been reported from 32 states and Union Territories, these cases are not evenly spread out across the country. States like Maharashtra, Gujarat, Delhi, Tamil Nadu, Rajasthan, Uttar Pradesh, and Madhya Pradesh have emerged as epic centers and are the worst-hit states in India in terms of the total number of Covid-19 cases that have been reported. ${ }^{[7]}$ In response, India has implemented international travel bans and a strict lockdown from March 25, 2020. The first phase of lockdown ended on 14th April, followed by the second phase ended on 03rd May, and at present 3rd phase of lockdown is going on until May 17th. However, countries like India are at larger risk because of a very large population density, illiteracy, and inadequate healthcare systems to cater to very large demands ${ }^{[8]}$. In epidemiology, a case fatality rate (CFR), sometimes called case fatality risk is the percentage of cases of a specified condition that is fatal within a definite time. A CFR is conventionally expressed as a percentage and represents a measure of disease severity. ${ }^{[9]}$ CFRs reflect the level of disease severity and CFR is vital for setting priorities for public health in targeted interventions to reduce the severity of the risk. High CFRs reflect limited access to proper health care for the most vulnerable people and insufficiencies in health-care systems, including the limited capacity of the surveillance system to trigger a timely response. ${ }^{[10]}$ As of the end of the Lockdown 1.0 \& 2.0 (i.e. 14th April \& 3rd May respectively) the CFR of India is at 3.26 \& 3.34 respectively for COVID-19 but the CFR's of states of India has not been reported until now, which may be helpful in understanding and estimating the fatality and sternness of this infectious disease in the Indian subcontinent. The first robust and ideal step in mitigating the outbreak of communicable diseases like COVID-19 is for government health officials to begin early testing. This leads to rapid identification of cases, fast isolation to prevent spread, contact tracing, and swift initiation of treatment. Early testing is the only way to recognize anyone who came into contact with infected people so they can be isolated from the community and may hastily be treated. Testing also is important in the larger public health picture on mitigation efforts, helping investigators to depict the prevalence, spread, and contagiousness of the disease. Due to the limited resources, the testing rate in India is among the lowest in the world, which may underestimate the total number of confirmed cases. ${ }^{[3,4]}$ Thus it is essentially required to estimate the total test rate and percentage of positive cases. Keeping the above in mind, the present study was aimed to perform a retrospective analysis of the total number of test performed by different states, total no. of confirmed cases and $\%$ of positivity rate reported initially in India during the first lockdown (1.0) and the second phase (2.0) of lockdown. Further, bearing in mind the prominence of CFR and RR in COVID 19 analysis, measurement and comparison of the same was done for different states of India at the end of Lockdown $1.0 \& 2.0$ using up-to-date state-level data.

\section{Methods:}

2.1. Source of data and procedure: The data were retrieved from accurate databases including Ministry of Health and family welfare (MoHFW) ${ }^{[11]}$, Centre for Evidence Based Medicine (CEBM) ${ }^{[12]}$, COVID19 India, and World Health Organization $(\mathrm{WHO})^{[13]}$. The analysis of data in the present study was carried from. 22nd March to 14th of April .i.e. first phase of lockdown and $15^{\text {th }}$ April to 3rd May, 2020, i.e. second phase of lockdown.

1. Parameters used in study: States with total cases [?] 100 were included in the study and raw data was mapped according to states. Percentage of confirmed cases (PCC), average tests per day CFR and RR were estimated and compared among states.

\section{Measuring the CFR and $\mathrm{RR}^{[14]}$ :}

The formulas below were used to measure PCC, CFR and RR-

PCC $(\%)=($ Number of test performed for COVID-19/Number of Confirm COVID-19 cases $) \times 100$

CFR $(\%)=($ Number of deaths due to COVID-19/ Number of reported cases of COVID-19) $\times 100$

$\mathrm{RR}(\%)=($ Number of cases recovered from COVID-19/ Number of reported cases of COVID19 $) \times 100$

Results: 
The geographical spread of coronavirus outbreak in India had extended to 31 states and Union Territories after 1st phase of lockdown with an addition of one state during 2nd phase of lockdown taking the tally to total of 32 as of now, with Mizoram being the latest to report Covid-19 cases. Totally 15 \& 18 no. of states have crossed 100 cases mark after completion of 1st\& 2nd phases of lockdown respectively. Average testing per day and \% of confirmed cases of COVID- 19 among states of India after lockdown $1.0 \& 2.0$

\subsection{Average testing per day and \% of confirmed cases of COVID 19 among states of India after Lockdown 1.0:}

Interstate analysis of testing after first phase of lockdown revealed that, $\%$ of confirmed cases of some states like, Delhi (9.27\%), Madhya Pradesh (7.45\%), West Bengal (6.16\%) and Tamil Nadu (6.09\%) are very high in comparison to pan India (4.68\%). However Karnataka and Kerala recorded lowest \% of confirmed cases i.e. $2.22 \%$ and $2.33 \%$, while remaining states recorded between $3-5.6 .8 \%$ (Table no.01 \&Figure no.01). In case of average tests/day, Maharashtra and Rajasthan have performed highest no. of tests, with average rate of 1955.7 and 1663.2 tests/day while, West Bengal, Jammu and Kashmir and Haryana have performed least no. of test with average rate of 146.7, 219.9, 230.6 and 248.0 tests/day respectively (Table no. 01\& Figure no.02). Average testing per day and \% of confirmed cases of COVID 19 among states of India after

\subsection{Average testing per day and \% of confirmed cases of COVID 19 among states of India after Lockdown 2.0:}

After the second phase of lockdown, data showed that \% of confirmed cases of Maharashtra (8.96\%), Delhi (7.24\%) Madhya Pradesh (5.43\%), Punjab (4.32\%) and West Bengal (3.89\%) are still high in comparison to pan India level (3.29\%) (Table no.01 \& Figure no.01).Average tests/day data reveals that that Tamil Nadu, Maharashtra, Andhra Pradesh, Uttar Pradesh, Rajasthan, Gujarat and Karnataka have accelerated the testing rate enormously and performed highest no. of tests, with highest average tests per day. On the other hand, West Bengal, Jammu \& Kashmir, Punjab and Haryana has done least no. of tests per day on comparison with other Indian states (Table no. 01 \& Figure no.02). All India data related to \% of confirmed cases and average tests/day, after second phase of lockdown showed remarkable improvement in comparison to first lockdown. Data of Telangana state was not available for analysis.

\subsection{Comparison of CFR's after 1st and 2nd phases of lockdown:}

After completion of 1st phase of lockdown, total no. of confirmed cases in India was 10,814 and 358 deaths was reported with CFR 3.26\%, compared to 39093 confirmed cases and 1306 deaths with CFR 3.34\% (Table no. 03). The total number of confirmed cases of COVID-19 was highest in Maharashtra after completion of 1st phase and 2nd phases of lockdown. However, Madhya Pradesh's CFR was highest after 1st\& 2nd phases of lockdown i.e.7.11\% and 5.48\%.Six states have shown an increase in CFR while eight states have shown decrease in CFR after completion of 2nd phase of lockdown compared to 1st phase. India on total has shown improvement in CFR rate after completion of 2nd phase of lockdown compared to 1st phase (Table no .02 \&Figure no. 03).

3.4. Comparison of RR's after 1st and 2nd phases of lockdown:The highest RR was observed in Kerala with RR values of $52.2 \%$ \& $80 \%$ compared with the overall India RR of $10.99 \%$ \& $27.84 \%$ after completion of 1st\& 2nd phases of phases of lockdown respectively. Except West Bengal, all the other states and union territories showed an improvement in RR's after completion of 2nd phase of lockdown compared

to 1st phase. The total number of exact people infected with COVID-19 may be higher than the number of known confirmed cases, mainly due to limited testing and asymptomatic cases (Table no.02 \&Figure no. 03).

\section{Discussion:}

India's testing rate was on lower-end matched to other countries in a fight against COVID- 19 until 03rd May 2020 but on the other hand \% of confirmed cases after testing was lower (3.57\%) when compared with Italy (23\%), Austria (16.7\%), US (13.5\%) and UK (10\%).[15]. This may indicate that the COVID 19 is still under the Phase 2 stage in India and also highpoint the efforts of the Indian government. Interstate analysis of lockdown 1.0 and 2.0 shows that some states especially West Bengal, Jammu \& Kashmir, Punjab 
and, Haryana have very smaller no. of testing rates, while Tamil Nadu, Maharashtra, Andhra Pradesh, Uttar Pradesh, Rajasthan, Gujarat, and Karnataka have accelerated the testing and data showed a high shift in testing rate in these states during the second phase of lockdown. Impact of social distancing and lockdown can be observed clearly in this study where the total no of cases and \% of confirmed cases have declined in states after lockdown 2.0 except Maharashtra. However, the analysis of both the phases 1.0 and 2.0 is quite encouraging, showing positive impact supporting the lockdown initiative of Govt. of India at pan India level. Despite this, the results of the study is a wakeup call for a few states where the testing rate is very less, and \% of confirmed cases are high. The testing rate should be accelerated in these states to stop the asymptomatic transmission. Low testing rates may create a panic situation in the future, and undiagnosed cases may lead to community transmission that can create a dangerous situation for populations. Thus it is essentially required, states and central govt. may unite together to build the testing facility and accelerate the testing.

Currently, the mitigation measures adopted by the Indian government had effectively reduced the spread and flattened the now ubiquitous curve to allow health care providers to provide effective care to those in critical need as evidenced by the decrease in $\%$ of confirmed cases. But the critical question remains what the future holds because lockdown can't remain all time, thus during the lockdown, it is essential to test the maximum population in high positive percentage areas so that the symptomatic and asymptomatic cases can be traced and separated. Based on the results obtained in our study, we attempt to answer these questions in a rigorous evidence-based manner. At a fundamental level, epidemics spread over a network where carriers spread diseases with whom they are connected to some degree. These networks or 'links' can be via person to person interaction, local transport or travel, or via shared spaces/ surfaces. The geographic location of the networks is relevant because there may be different modes of spread that can exist within any region. The mitigation procedures cannot completely break this human to human 'link' to disconnect the communities, and hence we recommend policymakers and govt. to employ epidemiological studies and serological test cards to screen the asymptomatic cases. Classical epidemiological models are based on serological testing and utilized in past to estimate a reproduction number or R0 (pronounced as R-naught) to describe the intensity of the outbreak and is defined as the average number of infectious. For large scale serological testing, private labs should also be roped in, which will be helpful to accelerate the testing and can screen the COVID-19 asymptomatic cases at a fast track level.

Cross-state comparisons of CFR and RR as important indicators of disease characteristics are critical for national priority setting and recognizing health system performance.[9] In the initial phases of an epidemic, CFR tends to be on the higher side and this overestimation is due to under testing and a time-lag bias, which is more pronounced at the beginning of an outbreak. Although India is in initial phases of COVID-19, estimating CFR and RR are of vital importance as they denote the current status of the pandemic and helps in planning the additional measures to be adopted to tackle the pandemic effectively. Hence, this study was aimed to measure the CFR and RR of different states having at least $>100$ confirmed cases in India during the ongoing COVID-19 pandemic using recent state-level data after the 1st\& 2nd phases of lockdown i.e. 14th April \& 03rd May 2020.

Globally, India was in no.32 position in CFR after 1st phase of lockdown and no. 44 position after 2nd phase of lockdown. The improvement in CFR may be attributed to the mitigation measures adopted by the government like complete lockdown, strict social distancing, closure of intra \& interstate transport, improvement of testing facilities, awareness programs, self-quarantine and mandatory use of preventive appliances i.e. face mask, hand hygiene, etc., during this period. CFR of eight states has decreased after the completion of the 2nd phase of lockdown compared to 1st phase, indicating the success of mitigation measures adopted by the general public and government. Still, India needs to tackle the menace of low case testing, asymptomatic cases, undetected cases, or delayed case reporting to decrease the CFR on a pan India basis. The study also shows that RR of COVID- 19 has improved in all the analyzed states except West Bengal hinting the strength of clinicians, paramedical staff, and health care workers in the management of this disease with the available medications advised by Indian Council of Medical Research (ICMR). However, limited infrastructure and health care facilities available in India for the 1.3 billion populations (approx.) pose a challenge for 
the government authorities and policymakers in containing this disease further. Therefore, strategies must be developed including early detection of COVID-19 followed by access to medical care, which may enhance the chances of recovery rates. Besides, case studies with a detailed and accurate medical history, and scoring CFR alongside RR, should be adopted in hospitals which may be helpful in exactly pointing the hotspots of infection. This will, in turn, help the government authorities in identifying the areas with higher infection rates, so that lockdown can be strictly carried out in that parts of the country and necessary medical resources will be mobilized to that areas. Thus, the extended lockdown may provide more time to identify the asymptomatic cases and prevent community transmission at the state level.

5. Conclusion : Indian states have shown a tremendous improvement concerning testing and mitigation measures to fight against COVID- 19 as evidenced by a decrease in \% of confirmed cases, CFR, and improvement in RR. Further, employing mass testing and epidemiological studies will strengthen the health care infrastructure and will augment the screening the asymptomatic cases.

\section{Conflicts of interest}

The authors have none to declare.

\section{References:}

1. Morens DM, Daszak P, Taubenberger JK. Escaping Pandora's Box-another novel coronavirus. N Engl J Med. 2020; 382:1293-1295.

2. World Health Organization, Coronavirus (COVID-19) Last updated: 2020/5/3, 9:00am CEST. https://covid19.who.int/

3. Coronavirus: India defiant as millions struggle under lockdown". BBC. 28 March 2020. Retrieved 28 March 2020.

4. One COVID-19 positive infects 1.7 in India, lower than in hot zones". The Indian Express. 19 March 2020.

5. Pang J, Wang MX, Ang IYH, Tan SHX, Lewis RF, Chen JI, et al. Potential Rapid Diagnostics, Vaccine and Therapeutics for 2019 Novel Coronavirus (2019-nCoV): A Systematic Review. J Clin Med. 2020;9:doi: 10.3390/jcm9030623.

6. Tanu S. A review of coronavirus disease-2019 (COVID-19). Indian J Pediatr. 2020; 87: 281-286

7. Ministry of Health and Family Welfare, Government of India. COVID-19 INDIA;2020;April .https://www.mohfw.gov.in/

8. Yueling M, Yadong Z, Jiangtao L, Xiaotao H, Bo W, Shihua F, et al. Effects of temperature variation and humidity on the mortality of covid-19 in Wuhan. Sci Total Environ. 2020;724:138226.

9. Kanchan T, Kumar N, Unnikrishnan B. Mortality: Statistics. In: Encyclopedia of Forensic and Legal Medicine, 2nd ed. Elsevier Inc: 2015. p. 572-7.

10. Reich NG, Lessler J, Cummings DAT, Brookmeyer R. Estimating absolute and relative case fatality ratios from infectious disease surveillance data.

11. Ministry of Health and Family Welfare, GOI". www.mohfw.gov.in .

12. World Health Organization Overview Coronavirus disease (COVID-19) Situation dashboard, latest global numbers and numbers by country of COVID-19 cases on a daily basis.

13. Centre for Evidence Based Medicine (CEBM). Global Covid-19 Case Fatality Rates. 14thApril, 2020. https://www.cebm.net/covid-19/global-covid-19-case-fatality-rates/

14. Morteza AK, Fakher R. Cross-Country Comparison of Case Fatality Rates of COVID19/SARS-COV-2. Osong Public Health.

15. Data as on March 26, 2020 Sources: Korea Centers for Disease Control and Prevention; Ministry of Health, Italy; Department of Health and Social Care and Public Health England; The Covid Tracking Project Taiwan Centers for Disease Control; Indian Council of Medical Research; Ministry of Social Affairs, Austria https://www.bloombergquint.com/coronavirus-outbreak/1-in-50-covid-19-tests-inindiaare-coming-out-positive-compared-with-1-in-4-in-italy-1-in-10-in-the-uk

Table no.01 : Average testing per day and \% of confirmed cases of COVID 19 among states of 
India after completion of 1st phase and 2nd phases of lockdown.

\begin{tabular}{|c|c|c|c|c|}
\hline Indian states & $\begin{array}{l}\text { Tested cases } \\
\text { (cumulative) }\end{array}$ & $\begin{array}{l}\text { Detected cases } \\
\text { (cumulative) }\end{array}$ & $\begin{array}{l}\text { \% of confirmed } \\
\text { cases } \\
\text { (cumulative) }\end{array}$ & $\begin{array}{l}\text { Avg. tests/per } \\
\text { day (cumulative) }\end{array}$ \\
\hline Lockdown 1.0 & Lockdown 1.0 & Lockdown 1.0 & Lockdown 1.0 & Lockdown 1.0 \\
\hline First Phase & First Phase & First Phase & First Phase & First Phase \\
\hline Andhra Pradesh & 10505 & 432 & 4.11 & 500.2 \\
\hline Delhi & 16282 & 1510 & 9.27 & 814.1 \\
\hline Gujarat & 14980 & 539 & 3.59 & 713.3 \\
\hline Haryana & 5210 & 185 & 3.55 & 248 \\
\hline Jammu and & 4619 & 270 & 5.84 & 219.9 \\
\hline \multicolumn{5}{|l|}{ Kashmir } \\
\hline Karnataka & 11107 & 247 & 2.22 & 528.9 \\
\hline Kerala & 16235 & 379 & 2.33 & 773.0 \\
\hline Madhya Pradesh & 8105 & 604 & 7.45 & 385.9 \\
\hline Maharashtra & 41071 & 2334 & 5.68 & 1955.7 \\
\hline Punjab & 4844 & 167 & 3.44 & 230.6 \\
\hline Rajasthan & 34928 & 873 & 2.49 & 1663.2 \\
\hline Tamilnadu & 19255 & 1173 & 6.09 & 916.9 \\
\hline Uttar Pradesh & 15914 & 558 & 3.5 & 757.8 \\
\hline West Bengal & 3081 & 190 & 6.16 & 146.7 \\
\hline India & 237753 & 11145 & 4.68 & 11321.5 \\
\hline Lockdown 2.0 & Lockdown 2.0 & Lockdown 2.0 & Lockdown 2.0 & Lockdown 2.0 \\
\hline Second Phase & Second Phase & Second Phase & Second Phase & Second Phase \\
\hline Andhra Pradesh & 104432 & 1151 & 1.1 & 5221.6 \\
\hline Delhi & 41928 & 3039 & 7.24 & 2096.4 \\
\hline Gujarat & 65080 & 4689 & 7.2 & 3254 \\
\hline Haryana & 29768 & 257 & 0.86 & 1488.4 \\
\hline $\begin{array}{l}\text { Jammu and } \\
\text { Kashmir }\end{array}$ & \multicolumn{3}{|c|}{ Kashmir } & 1070.9 \\
\hline Karnataka & 63791 & 367 & 0.57 & 3189.5 \\
\hline Kerala & 15982 & 121 & 0.94 & 799.1 \\
\hline Madhya Pradesh & 41081 & 2233 & 5.43 & 2054.0 \\
\hline Maharashtra & 118683 & 10640 & 8.96 & 5934.1 \\
\hline Punjab & 21595 & 935 & 4.32 & 1079.7 \\
\hline Rajasthan & 85312 & 2136 & 2.5 & 4265.6 \\
\hline Tamilnadu & 130854 & 1850 & 1.41 & 6542.7 \\
\hline Uttar Pradesh & 79927 & 2087 & 2.61 & 3996.3 \\
\hline West Bengal & 19834 & 773 & 3.89 & 991.7 \\
\hline Pan India & 956957 & 31569 & 3.29 & 47847.8 \\
\hline
\end{tabular}

Table no.02: Comparison of case fatality rates and recovery rates between states after completion of $1^{\text {st }}$ phase and $2^{\text {nd }}$ phases of lockdown.

\begin{tabular}{lllllll}
\hline State & Total cases & Total deaths & Active cases & Total recovered & CFR (\%) & RR (\%) \\
\hline Andhra Pradesh & 432 & 7 & 414 & 11 & 1.62 & 2.54 \\
Delhi & 1510 & 28 & 1452 & 30 & 1.85 & 1.98 \\
Gujarat & 539 & 26 & 459 & 54 & 4.82 & 10.01 \\
Haryana & 185 & 03 & 153 & 29 & 1.62 & 15.67
\end{tabular}




\begin{tabular}{lllllll}
\hline State & Total cases & Total deaths & Active cases & Total recovered & CFR (\%) & RR (\%) \\
\hline Jammu and Kashmir & 270 & 04 & 250 & 16 & 1.4 & 5.92 \\
Karnataka & 247 & 06 & 182 & 59 & 2.42 & 23.8 \\
Kerala & 379 & 03 & 178 & 198 & 0.79 & 52.2 \\
Madhya Pradesh & 604 & 43 & 517 & 44 & 7.11 & 7.28 \\
Maharashtra & 2334 & 160 & 1957 & 217 & 6.85 & 9.29 \\
Punjab & 167 & 11 & 142 & 14 & 6.58 & 8.38 \\
Rajasthan & 873 & 03 & 849 & 21 & 0.34 & 2.40 \\
Tamilnadu & 1173 & 11 & 1104 & 58 & 0.93 & 4.94 \\
Telangana & 562 & 16 & 446 & 100 & 2.84 & 17.79 \\
Uttar Pradesh & 558 & 05 & 504 & 49 & 0.89 & 8.78 \\
West Bengal & 190 & 07 & 143 & 36 & 3.68 & 18.94 \\
India & $\mathbf{1 0 8 1 4}$ & $\mathbf{3 5 3}$ & $\mathbf{9 2 7 2}$ & $\mathbf{1 1 8 9}$ & $\mathbf{3 . 2 6}$ & $\mathbf{1 0 . 9 9}$ \\
Andhra Pradesh & 1583 & 33 & 1062 & 488 & 2.08 & 30.82 \\
Delhi & 4122 & 64 & 2802 & 1256 & 1.55 & 30.47 \\
Gujarat & 5055 & 262 & 3897 & 896 & 5.18 & 17.72 \\
Haryana & 394 & 4 & 163 & 227 & 1.01 & 57.61 \\
Jammu and Kashmir & 666 & 8 & 404 & 254 & 1.20 & 38.13 \\
Karnataka & 606 & 25 & 299 & 282 & 4.12 & 46.56 \\
Kerala & 500 & 4 & 96 & 400 & 0.8 & 80 \\
Madhya Pradesh & 2846 & 156 & 1892 & 798 & 5.48 & 28.03 \\
Maharashtra & 12296 & 521 & 9775 & 2000 & 4.23 & 16.26 \\
Punjab & 772 & 20 & 640 & 112 & 2.59 & 14.50 \\
Rajasthan & 2772 & 65 & 1586 & 1121 & 2.34 & 40.44 \\
Tamil Nadu & 2757 & 29 & 1387 & 1341 & 1.05 & 48.63 \\
Telangana & 1063 & 28 & 577 & 458 & 2.63 & 43.08 \\
Uttar Pradesh & 2626 & 43 & 1885 & 698 & 1.63 & 26.58 \\
West Bengal & 922 & 33 & 738 & 151 & 3.57 & 16.37 \\
Bihar & 482 & 04 & 361 & 117 & 0.82 & 24.27 \\
Jharkhand & 115 & 03 & 90.34 & 19.13 \\
Odisha & 160 & 01 & 103 & 22 & 56 & 27.84 \\
India & 39093 & 1306 & 28070 & 10887 & & 35 \\
\hline & & & & & \\
\end{tabular}

Figure no: 01. Comparison of \% of confirmed cases among states of India after completion of $1^{\text {st }}$ phase and $2^{\text {nd }}$ phases of lockdown. 
Figure no: 02. Comparison of average tests/day among states of India after completion of $1^{\text {st }}$ phase and $2^{\text {nd }}$ phases of lockdown.

Figure no: 03. Comparison of case fatality rate (CFR) among states of India after completion of $1^{\text {st }}$ phase and $2^{\text {nd }}$ phases of lockdown. 
Figure no: 04. Comparison of recovery rates (RR) among states of India after completion of $1^{\text {st }}$ phase and $2^{\text {nd }}$ phases of lockdown. 